\title{
Additional impact of mutational genotype on prognostic determination in resistant and relapsed acute myeloid leukaemia
}

David C Linch ${ }^{a}$, Robert K Hills ${ }^{b}$, Amanda Gilkes ${ }^{c}$, Alan K Burnettc, Nigel Russell ${ }^{d}$, Rosemary E Gale ${ }^{a}$

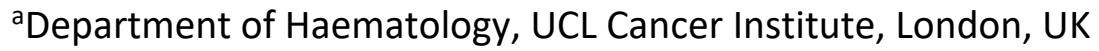

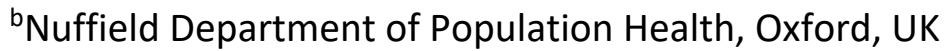

'Department of Haematology, School of Medicine, Cardiff University, Cardiff, UK

${ }^{\mathrm{d} D e p a r t m e n t}$ of Haematology, Nottingham University Hospital NHS Trust, Nottingham, UK

Correspondence to:

Professor David Linch,

Department of Haematology, University College London Cancer Institute, Paul O'Gorman Building, 72 Huntley Street, London WC1E 6DD, UK.

e-mail: david.linch@ucl.ac.uk

Phone: (+44)-20-7679-6221

Fax: (+44)-20-7679-6222 


\section{ABSTRACT}

Outcome after failure of initial therapy in younger adult patients with acute myeloid leukaemia (AML) is highly variable. Cytogenetics, length of first remission (CR1) before relapse, and allogeneic transplantation are known prognostic factors, but the contribution of leukaemic genotype is less clear, particularly in resistant disease. Of 5,651 younger adult patients entered into UK MRC/NCRI AML trials between 1988 and 2014 with available FLT3 ${ }^{1 T D}$ and NPM1 genotype, 326 (6\%) had resistant disease and 2338 (41\%) relapsed after achieving CR1. Overall survival (OS) was significantly higher in relapsed compared to resistant disease $(p=0.03)$. Independent favourable prognostic factors for OS in resistant disease included lower blast cell percentage after two courses of induction therapy $(p=0.0006)$ and NPM1 mutant $\left(N P M 1^{M U T}\right)(p=0.04)$. In relapsed disease, longer CR1 was a favourable independent factor for attainment of CR2 $(p<0.0001)$ and OS from time of relapse $(p<0.0001)$, but CR2 rate and OS from relapse were significantly worse in those who had received an allograft in CR1 (respectively $\mathrm{p}<0.05, \mathrm{p}<0.002$ ). NPM1 ${ }^{\mathrm{MUT}}$ was marginally beneficial for OS ( $p=0.04)$. FLT3 $3^{\mathrm{ITD}}$ and DNMT3A ${ }^{\mathrm{MUT}}$ were adverse factors for OS (respectively $\mathrm{p}<0.0001, \mathrm{p}=0.02$ ). Mutational analysis adds additional independent prognostic information to demographic features and previous therapy in patients with resistant and relapsed disease.

Keywords:

Acute myeloid leukaemia Leukaemic cell genotype Prognostic factors Resistant disease Relapse post first remission NPM1 mutation 


\section{Introduction}

Risk-adapted therapy is standard practice in the treatment of acute myeloid leukaemia (AML), with particular reference to the type of consolidation therapy given in first complete remission (CR1). Allogeneic haematopoietic stem cell transplantation in CR1 is usually offered to younger patients deemed to have a high risk of relapse, with variable use of transplantation in those with intermediate-risk disease. Few centres would consider consolidation with an allogeneic transplant in patients with favourable-risk disease. Risk factors include patient age, WHO performance status (PS), presenting white blood cell count (WBC) and the cytogenetic risk group [1]. Mutational analysis provides further prognostic information and is incorporated into most therapeutic guidelines for first-line therapy [2,3]. Thus, the presence of an NPM1 mutation (NPM1 $\left.{ }^{\mathrm{MUT}}\right)$ without a $F L T 3$ internal tandem duplication $\left(F L T 3^{I T D}\right)$ is associated with a favourable outcome $[4,5]$, as is biallelic mutation of the CEBPA gene $[6,7]$. The presence of a $F L T 3^{I T D}$ is a poor prognostic factor, particularly when the $F L T 3^{\mid T D}$ variant allele frequency (VAF) is high $[4,8]$. The presence of a DNMT3A mutation $\left(D N M T 3 A^{\mathrm{MUT}}\right)$ is also a poor prognostic factor in most series [9-11].

In patients failing first-line therapy, either failing to achieve a CR after initial induction therapy or relapsing from CR1, there is general agreement that the cytogenetic risk category, the length of CR1 in those that relapse, and whether or not the patient received an allogeneic transplant in CR1 are all important prognostic factors [12-15]. There is less clarity about the value of the presenting leukaemic cell genotype, particularly in those patients deemed to have resistant disease following initial therapy. The analysis is compounded by the fact that some reports refer to relatively small cohorts of patients, resistant disease patients and relapsed disease patients are often considered together, and there are significant differences in how resistant disease is defined $[14,16,17]$.

Understanding the likely outcome of patients failing first-line therapy, and the factors influencing this, is not just important for the provision of accurate information to patients, but also for the development of novel therapies. New agents are often 'targeted therapies' and as these may only be appropriate for relatively small subsets of patients, it is difficult to conduct adequately powered randomised trials. Initial studies in the relapsed and resistant setting are, therefore, often singlearm studies. Furthermore, this may be the only information available to license such drugs, for example, as with the Food and Drug Administration approvals for gilteritinib, ivosidenib and 
enasidenib (see https://www.fda.gov/), and a good appreciation of the natural history of such patients treated without the new agents is essential.

We have, therefore, analysed the outcome of a large series of patients entered into four consecutive UK National Trials for AML in younger adult patients who were either deemed to be refractory to two cycles of intensive induction therapy containing both an anthracycline and cytosine arabinoside, or who relapsed after achieving CR1.

\section{Methods}

\subsection{Patients}

Between 1988 and 2014, 9,396 patients aged between 16 and 64 years were entered into consecutive UK Medical Research Council AML10, AML12 (ISRCTN17833622), AML15 (ISRCTN17161961), and National Cancer Research Institute AML17 (ISRCTN55675535) trials for patients with newly diagnosed non-M3 AML [18-21]. Informed patient consent was obtained in accordance with the Declaration of Helsinki; ethical approval for tissue use from the Wales Research Ethics Committee 3. The mutational status for NPM1 and FLT3 was available in 5,651 of these patients and this is the cohort analysed here. The genotyped patients had a number of significantly different characteristics from those patients who were not genotyped, but this was largely due to the large population sizes rather than the magnitude of differences between the different populations (Supplementary Table A.1). A greater proportion of patients were genotyped in the later trials, when genotyping had become a more routine procedure, and as genotyped patients tended to have a higher presenting WBC (median $13.9 \times 10^{9} / \mathrm{L}$ vs $8.6 \times 10^{9} / \mathrm{L}, \mathrm{p}<0.0001$ ), more stored material was available from these patients for genotyping. Overall survival (OS) at 5 years was significantly greater in those patients who were genotyped ( $43 \%$ vs $38 \%, p<0.0001$ unadjusted), but this was reduced to a trend after adjustment for other prognostic variables including the date of trial entry ( $p=0.09$ ) (Supplementary Table A.2). This difference was mainly due to a lower early mortality in the genotyped patients, and the adjusted OS post day 30 was not significantly different (hazard ratio [HR] 0.98 [95\% confidence intervals 0.92-1.05]; $p=0.6$ ). In the cohort analysed here, there was little change in the CR rate over the course of the four trials ( $81 \%$, $85 \%, 86 \%$, and $87 \%$ respectively), no significant change in 5-year relapse-free survival (38\%, $35 \%$, $39 \%$ and $39 \%$ ) but a progressive improvement in 5-year OS (35\%, 39\%, 42\% and $46 \%)$. 
Of the 5,651 patients, 326 (6\%) were alive and deemed not to be in remission after two cycles of induction therapy and are classified here as resistant disease, in accord with ELN recommendations [2]. A further 2,338 patients (41\%) relapsed after achieving CR1; the median duration of CR1 was 9.8 months (range, 0.2-147). Of note, 59 patients classified as resistant disease achieved a late CR and subsequently relapsed so are also included in the relapsed disease cohort ( $2.5 \%$ of all relapsed patients). In the relapsed disease patients, CR1 was achieved after one cycle of induction therapy in 1840 patients (79\%), two cycles in 331 patients (14\%), and after more cycles in 59 patients (2.5\%). Data is incomplete in $4 \%$ of the patients.

\subsection{Molecular analyses}

Molecular analyses were performed on diagnostic samples either at the time of diagnosis or retrospectively using stored material. Mutations in the FLT3, NPM1, DNMT3A, CEBPA, IDH1 and $I D H 2$ genes were investigated and $F L T 3^{I T D}$ VAF was quantified as previously described $[4,7,11,22]$.

\subsection{Clinical endpoints}

CR was defined as a normo-cellular bone marrow containing $<5 \%$ blasts and showing evidence of normal maturation of other marrow elements. Peripheral blood regeneration was not a requirement but $95 \%$ of cases defined as in CR achieved a neutrophil count $>1 \times 10^{9} / \mathrm{L}$ and a platelet count $>100 \times 10^{9} / \mathrm{L}$. The cumulative incidence of relapse (CIR) was defined as the time from remission to relapse, with death in remission as a competing risk. OS was the time from randomisation to death.

\subsection{Statistical analysis}

Mantel-Haenszel and $\chi^{2}$ tests were used to test for differences in demographic and clinical data. Kaplan-Meier curves were constructed for CIR and OS data and compared by means of the log-rank test, with standard tests for heterogeneity between subgroups. Multivariable Cox analysis (MVA) was used for CIR and OS. Because some data was not available for all patients, a two-stage process was used for the model building; first the variables with minimal missing data were used and then other variables were explored to see if they added to the best parsimonious model. All $p$ values are two-tailed. 


\section{Results}

3.1. Comparative demographics and outcomes of patients with resistant and relapsed disease The median age of the 326 patients with resistant disease was 49 years (range, 16-64), 58\% were male, $94 \%$ had a PS $\leq 2$, median presenting WBC was $13.3 \times 10^{9} / \mathrm{L}$ (range, $0.8-456$ ) and $14 \%$ had secondary disease (Table 1 ). There were only five resistant disease patients (2\%) with favourablerisk cytogenetics, 174 (60\%) had intermediate-risk cytogenetics and $113(39 \%)$ had adverse-risk cytogenetics as defined by the MRC classification [23]. No patient with resistant disease received an allograft before being designated as having this disease status, but 101 (31\%) did achieve a CR with further therapy, of which 50 (15\% of total group) went on to receive an allogeneic transplant. For the 2,338 relapsed disease patients, median age, PS at initial presentation, median presenting WBC and the incidence of secondary disease were all similar to that of the resistant disease patients (Table 1). A larger proportion of relapsed disease patients had favourable-risk cytogenetics (12\%) $(p<0.0001)$ and fewer had adverse-risk cytogenetics (14\%) ( $p=0.0004)$. Overall, 302 of the relapsed disease patients (13\%) received an allograft in CR1.

The OS for all patients from the time of designation as resistant disease was $30 \%$ at 1 year and $14 \%$ at 5 years. Of the patients with relapsed disease, $1164(50 \%)$ achieved a second CR, which is significantly higher than the ultimate CR rate in those with resistant disease $(p<0.0001)$, and 501 (21\%) of these patients went on to have an allogeneic transplant in CR2. The OS for all patients with relapsed disease was $39 \%$ at 1 year from the time of relapse and $20 \%$ at 5 years, which is significantly higher than the OS for those with resistant disease (HR 1.29 [1.12-1.48]; $p=0.03$ ). If the 59 patients who appear in both cohorts are excluded from the relapsed disease cohort, then the significance of the difference in outcome increases (HR 1.50 [1.28-1.76]; $p<0.0001$ ). 


\begin{tabular}{|c|c|c|c|c|c|c|c|c|c|c|}
\hline \multirow[b]{2}{*}{ Characteristic } & \multicolumn{5}{|c|}{ Resistant Disease $(n=326)$} & \multicolumn{5}{|c|}{ Relapsed Disease $(n=2338)$} \\
\hline & $\begin{array}{c}\text { No. } \\
\text { (\% of group) }\end{array}$ & CR rate & $\begin{array}{c}\text { Impact on CR } \\
p \text { value }\end{array}$ & $\begin{array}{l}\text { OS at } 5 \\
\text { years }^{+}\end{array}$ & $\begin{array}{c}\text { Impact on OS } \\
\text { p value }\end{array}$ & $\begin{array}{c}\text { No. } \\
\text { (\% of group) }\end{array}$ & $\begin{array}{l}\text { Second } \\
\text { CR rate }\end{array}$ & $\begin{array}{c}\text { Impact on CR } \\
\text { p value }\end{array}$ & $\begin{array}{l}\text { OS at } 5 \\
\text { years }^{\ddagger}\end{array}$ & $\begin{array}{c}\text { Impact on OS } \\
\text { p value }\end{array}$ \\
\hline $\begin{array}{l}\text { Trial } \\
\text { AML10 } \\
\text { AML12 } \\
\text { AML15 } \\
\text { AML17 }\end{array}$ & $\begin{array}{c}54(17) \\
51(16) \\
80(25) \\
141(43)\end{array}$ & $\begin{array}{l}22 \% \\
41 \% \\
34 \% \\
29 \%\end{array}$ & $0 \cdot 2$ & $\begin{array}{c}2 \% \\
20 \% \\
11 \% \\
18 \%\end{array}$ & 0.03 & $\begin{array}{c}201(9) \\
460(20) \\
652(28) \\
1025(44)\end{array}$ & $\begin{array}{l}45 \% \\
48 \% \\
47 \% \\
53 \% \\
\end{array}$ & 0.05 & $\begin{array}{c}9 \% \\
17 \% \\
18 \% \\
24 \%\end{array}$ & $<0.0001$ \\
\hline $\begin{array}{l}\text { Age, years } \\
16-29 \\
30-39 \\
40-49 \\
50-59 \\
60-64 \\
\text { Median (range) }\end{array}$ & $\begin{array}{c}45(14) \\
50(15) \\
74(23) \\
121(37) \\
36(11) \\
49(16-64)\end{array}$ & $\begin{array}{l}33 \% \\
40 \% \\
34 \% \\
30 \% \\
14 \%\end{array}$ & $0 \cdot 1^{* *}$ & $\begin{array}{l}10 \% \\
18 \% \\
20 \% \\
12 \% \\
9 \%\end{array}$ & $0.7^{* *}$ & $\begin{array}{c}328(14) \\
358(15) \\
583(25) \\
848(36) \\
221(9) \\
48(16-64)\end{array}$ & $\begin{array}{l}65 \% \\
54 \% \\
54 \% \\
44 \% \\
33 \%\end{array}$ & $<0.0001^{* *}$ & $\begin{array}{c}29 \% \\
23 \% \\
23 \% \\
15 \% \\
7 \%\end{array}$ & $<0 \cdot 0001^{* *}$ \\
\hline $\begin{array}{l}\text { Sex } \\
\text { Female } \\
\text { Male }\end{array}$ & $\begin{array}{l}137(42) \\
189(58)\end{array}$ & $\begin{array}{l}32 \% \\
30 \%\end{array}$ & $0 \cdot 7$ & $\begin{array}{l}15 \% \\
13 \%\end{array}$ & $0 \cdot 2$ & $\begin{array}{l}1107(47) \\
1231(53)\end{array}$ & $\begin{array}{l}50 \% \\
49 \%\end{array}$ & 0.6 & $\begin{array}{l}23 \% \\
17 \%\end{array}$ & $0 \cdot 02$ \\
\hline $\begin{array}{c}\text { Disease Type } \\
\text { De Novo } \\
\text { Secondary }\end{array}$ & $\begin{array}{c}281(86) \\
45(14) \\
\end{array}$ & $\begin{array}{l}33 \% \\
16 \% \\
\end{array}$ & 0.02 & $\begin{array}{c}15 \% \\
7 \% \\
\end{array}$ & $0 \cdot 1$ & $\begin{array}{c}2159(92) \\
179(8) \\
\end{array}$ & $\begin{array}{l}51 \% \\
32 \% \\
\end{array}$ & $<0 \cdot 0001$ & $\begin{array}{c}20 \% \\
9 \% \\
\end{array}$ & $<0 \cdot 0001$ \\
\hline $\begin{array}{l}\text { WHO PS } \\
0 \\
1 \\
2 \\
\geq 3\end{array}$ & $\begin{array}{l}177(54) \\
95(29) \\
33(10) \\
21(6)\end{array}$ & $\begin{array}{l}33 \% \\
32 \% \\
21 \% \\
24 \% \\
\end{array}$ & $0 \cdot 2^{*}$ & $\begin{array}{c}19 \% \\
11 \% \\
3 \% \\
0 \%\end{array}$ & $0.0002^{*}$ & $\begin{array}{c}1411(60) \\
636(27) \\
191(8) \\
100(4)\end{array}$ & $\begin{array}{l}51 \% \\
49 \% \\
39 \% \\
53 \% \\
\end{array}$ & $0 \cdot 1^{*}$ & $\begin{array}{l}22 \% \\
18 \% \\
10 \% \\
16 \%\end{array}$ & $<0.0001^{*}$ \\
\hline $\begin{array}{l}\text { WBC, } \times 10^{9} / \mathrm{L} \\
0-9 \cdot 9 \\
10-49 \cdot 9 \\
50-99 \cdot 9 \\
\geq 100 \\
\text { Median (range) }\end{array}$ & $\begin{array}{c}140(43) \\
109(33) \\
37(11) \\
40(12) \\
13 \cdot 3(0 \cdot 8-456)\end{array}$ & $\begin{array}{l}30 \% \\
32 \% \\
30 \% \\
33 \%\end{array}$ & $0.99 * *$ & $\begin{array}{c}15 \% \\
17 \% \\
6 \% \\
7 \%\end{array}$ & $0 \cdot 1^{* *}$ & $\begin{array}{c}987(42) \\
750(32) \\
313(13) \\
288(12) \\
15 \cdot 2(0 \cdot 3-480 \cdot 0)\end{array}$ & $\begin{array}{l}48 \% \\
55 \% \\
50 \% \\
44 \%\end{array}$ & $0.6 * *$ & $\begin{array}{l}18 \% \\
23 \% \\
18 \% \\
19 \%\end{array}$ & $0.01 * *$ \\
\hline $\begin{array}{l}\text { Cytogenetics } \\
\text { Favourable } \\
\text { Intermediate } \\
\text { Adverse } \\
\text { Unknown } \\
\end{array}$ & $\begin{array}{c}5(2) \\
174(60) \\
112(39) \\
35 \\
\end{array}$ & $\begin{array}{l}80 \% \\
37 \% \\
21 \%\end{array}$ & $0.0005^{*}$ & $\begin{array}{c}80 \% \\
19 \% \\
4 \%\end{array}$ & $<0 \cdot 0001^{*}$ & $\begin{array}{c}250(12) \\
1572(75) \\
287(14) \\
229 \\
\end{array}$ & $\begin{array}{l}84 \% \\
50 \% \\
21 \%\end{array}$ & $<0.0001^{*}$ & $\begin{array}{c}45 \% \\
19 \% \\
4 \%\end{array}$ & $<0.0001^{*}$ \\
\hline $\begin{array}{l}\text { Courses to CR } \\
1 \\
2 \\
>2 \\
\text { Uncertain } \\
\text { No CR }\end{array}$ & $\begin{array}{c}-- \\
-- \\
101(31) \\
225(69)\end{array}$ & & & & & $\begin{array}{c}1840(79) \\
331(14) \\
59(3) \\
8(<1) \\
100(4)\end{array}$ & $\begin{array}{l}54 \% \\
37 \% \\
27 \%\end{array}$ & $<0.0001^{*}$ & $\begin{array}{c}22 \% \\
10 \% \\
6 \%\end{array}$ & $<0.0001^{*}$ \\
\hline
\end{tabular}




\begin{tabular}{|c|c|c|c|c|c|c|c|c|c|c|}
\hline $\begin{array}{l}\text { Blast cell \% post \#2 } \\
\quad 6-19 \% \\
>19 \%\end{array}$ & $\begin{array}{l}70(49 \%) \\
72(51 \%)\end{array}$ & $\begin{array}{l}53 \% \\
17 \%\end{array}$ & $<0 \cdot 0001$ & $\begin{array}{c}18 \% \\
1 \%\end{array}$ & $<0 \cdot 0001$ & Not applicable & & & & \\
\hline Allograft in CR1 & $\begin{array}{c}\text { Not } \\
\text { applicable }\end{array}$ & & & & & 302 (13\%) & $\begin{array}{c}32 \% \text { vs } \\
52 \%\end{array}$ & $<0.0001$ & $\begin{array}{c}11 \% \text { vs } \\
21 \%\end{array}$ & $<0.0001$ \\
\hline $\begin{array}{l}\text { Length of remission } \\
<6 \text { months } \\
6-12 \text { months } \\
12-24 \text { months } \\
\geq 24 \text { months }\end{array}$ & $\begin{array}{c}\text { Not } \\
\text { applicable }\end{array}$ & & & & & $\begin{array}{l}583(25) \\
869(37) \\
571(24) \\
315(13) \\
\end{array}$ & $\begin{array}{l}28 \% \\
50 \% \\
65 \% \\
62 \% \\
\end{array}$ & $<0.0001^{*}$ & $\begin{array}{c}7 \% \\
17 \% \\
29 \% \\
33 \% \\
\end{array}$ & $<0.0001^{*}$ \\
\hline $\begin{array}{l}\text { FLT3ITD } \\
\text { WT } \\
\text { Mutant }\end{array}$ & $\begin{array}{c}261(80) \\
65(20)\end{array}$ & $\begin{array}{l}32 \% \\
26 \%\end{array}$ & $0 \cdot 3$ & $\begin{array}{l}14 \% \\
11 \%\end{array}$ & 0.4 & $\begin{array}{c}1739(74) \\
599(26)\end{array}$ & $\begin{array}{l}54 \% \\
39 \%\end{array}$ & $<0 \cdot 0001$ & $\begin{array}{l}21 \% \\
14 \%\end{array}$ & $<0.0001$ \\
\hline $\begin{array}{l}\text { NPM1 } \\
\text { WT } \\
\text { Mutant } \\
\end{array}$ & $\begin{array}{c}284(87) \\
42(13)\end{array}$ & $\begin{array}{l}29 \% \\
48 \% \\
\end{array}$ & 0.01 & $\begin{array}{l}11 \% \\
31 \%\end{array}$ & 0.03 & $\begin{array}{l}1636(70) \\
702(30)\end{array}$ & $\begin{array}{l}50 \% \\
49 \% \\
\end{array}$ & 0.6 & $\begin{array}{l}19 \% \\
22 \%\end{array}$ & 0.5 \\
\hline $\begin{array}{l}\text { DNMT3A } \\
\text { WT } \\
\text { Mutant } \\
\text { Unknown }\end{array}$ & $\begin{array}{c}102(78) \\
29(22) \\
195\end{array}$ & $\begin{array}{l}24 \% \\
52 \%\end{array}$ & 0.003 & $\begin{array}{l}9 \% \\
21 \%\end{array}$ & $0 \cdot 1$ & $\begin{array}{c}673(66) \\
349(34) \\
1022\end{array}$ & $\begin{array}{l}55 \% \\
45 \%\end{array}$ & 0.004 & $\begin{array}{l}21 \% \\
19 \%\end{array}$ & 0.01 \\
\hline $\begin{array}{l}\text { CEBPA } \\
\text { WT } \\
\text { Monoallelic mutant } \\
\text { Biallelic mutant } \\
\text { Unknown }\end{array}$ & $\begin{array}{c}133(96) \\
5(4) \\
0 \\
188\end{array}$ & $\begin{array}{c}29 \% \\
20 \% \\
-\end{array}$ & NE & $\begin{array}{c}11 \% \\
0 \% \\
-\end{array}$ & $\mathrm{NE}$ & $\begin{array}{c}968(92) \\
39(4) \\
46(4) \\
1285\end{array}$ & $\begin{array}{l}49 \% \\
64 \% \\
65 \%\end{array}$ & $\begin{array}{c}0.03 \\
\text { Biallelic vs } \\
\text { rest }=0.04\end{array}$ & $\begin{array}{l}19 \% \\
21 \% \\
36 \%\end{array}$ & $\begin{array}{c}0.005 \\
\text { Biallelic vs } \\
\text { rest }=0.002\end{array}$ \\
\hline $\begin{array}{l}\text { IDH1 } \\
\text { WT } \\
\text { Mutant } \\
\text { Unknown }\end{array}$ & $\begin{array}{c}155(92) \\
13(8) \\
158 \\
\end{array}$ & $\begin{array}{l}25 \% \\
31 \%\end{array}$ & 0.7 & $\begin{array}{c}8 \% \\
15 \%\end{array}$ & 0.6 & $\begin{array}{c}1026(91) \\
96(9) \\
1216 \\
\end{array}$ & $\begin{array}{l}51 \% \\
49 \%\end{array}$ & $0 \cdot 7$ & $\begin{array}{l}19 \% \\
21 \%\end{array}$ & 0.5 \\
\hline $\begin{array}{l}\text { IDH2 } \\
\text { WT } \\
\text { Mutant } \\
\text { Unknown }\end{array}$ & $\begin{array}{c}190(89) \\
23(11) \\
113\end{array}$ & $\begin{array}{l}27 \% \\
43 \%\end{array}$ & $0 \cdot 1$ & $\begin{array}{l}11 \% \\
13 \%\end{array}$ & 0.4 & $\begin{array}{c}1312(90) \\
149(10) \\
877\end{array}$ & $\begin{array}{l}49 \% \\
56 \%\end{array}$ & $0 \cdot 1$ & $\begin{array}{l}19 \% \\
21 \%\end{array}$ & $0 \cdot 2$ \\
\hline
\end{tabular}

Abbreviations: CR, complete remission; CR1, first remission; NE, not evaluable (groups too small for reliable estimation); OS, overall survival; PS, performance status; WBC, white blood cell count; WT, wild-type

All p values are Chi-squared/logrank unless: *Mantel-Haenszel test for trend; **Wilcoxon rank sum test. ${ }^{\dagger}$ From the time of resistant disease. ${ }^{\ddagger}$ From the time of relapse.

\section{Table 1. Characteristics, genotype and the impact on response to therapy in univariate analysis of the patients studied with either} resistant or relapsed disease. 
3.2. Prognostic factors, excluding mutational genotype, in patients with resistant and relapsed disease

As patients with resistant and relapsed disease received different therapies and had significantly different outcomes, the prognostic factors in these two scenarios were considered separately.

\subsubsection{Resistant disease}

In patients with resistant disease, the blast cell percentage after the second course of induction therapy was, by definition, $\geq 5 \%$. Precise values were recorded in 142 (44\%) of the patients; the median percentage was $20 \%$ (range, $6-98 \%$ ), and those with a blast cell count $<20 \%$ had a better chance of achieving a CR than those with $\geq 20 \%$ (53\% vs $17 \%, p<0.0001)$. The OS was also longer in those patients with below median levels (43\% vs $17 \%$ at 1 year, $18 \%$ vs $1 \%$ at 5 years (HR 2.59 [1.79-3.74]; $p<0.0001)$. Other risk factors for attainment of $C R$ and OS that were significant in univariate analysis are shown in Table 1. In MVA excluding blast percentage after course 2 as data was only available in $44 \%$ of patients, the significant prognostic factors for survival were the cytogenetic risk group (HR 1.84 [1.44-2.34]; $p<0.0001)$, the PS (HR 1.2 [1.05-1.38]; $p=0.003)$, and the log of the WBC (HR 1.24 [1.02-1.50]; $p=0.03$ ) (Table 2). If the blast cell percentage in the bone marrow after course \#2 was put into the model post construction, it was also a significant factor (HR 0.51 [0.35-0.76]; $p=0.0006)$. In those patients with intermediate-risk cytogenetics, the ultimate CR rate was $37 \%$, the OS at 1 year was 39\% and at 5 years 19\%. In patients with adverse-risk cytogenetics, the CR rate was $21 \%$, the OS at 1 year was $17 \%$ and at 5 years it was only $4 \%$ (Fig. $1 \mathrm{~A}$ ).

\begin{tabular}{|c|c|c|c|c|c|c|}
\hline & \multicolumn{2}{|c|}{ Resistant disease } & \multicolumn{2}{|c|}{ Relapsed disease (all) } & \multicolumn{2}{|c|}{ Relapsed disease not allografted in CRI } \\
\hline & $\mathrm{HR}$ & $p$ & HR & $p$ & $\mathrm{HR}$ & $p$ \\
\hline Cytogenetics & $1 \cdot 84(1 \cdot 44-2 \cdot 34)$ & $<0.0001$ & $2.47(1.92-3.17)$ & $<0.0001$ & $1.73(1.55-1.94)$ & $<0.0001$ \\
\hline Duration of $\mathrm{CR}$ & N/A & & $0.89(0.86-0.93)$ & $<0.0001$ & $0.86(0.83-0.88)$ & $<0.001$ \\
\hline Date of trial & & & & $<0.0001$ & & $<0.0001$ \\
\hline Age per decade & & & $1.15(1.08-1 \cdot 24)$ & $<0.0001$ & $1 \cdot 15(1 \cdot 10-1 \cdot 20)$ & $<0.0001$ \\
\hline Blast cell \% post \#2 & $0.51(0.35-0.76)$ & 0.001 & & & & \\
\hline Allograft in CR1 & Not applicable & & $1.35(1.09-1.66)$ & 0.002 & Not applicable & \\
\hline Log WBC & $1.20(1.05-1.38)$ & 0.003 & $1.25(1.08-1.44)$ & 0.005 & $1 \cdot 11(1 \cdot 02-1 \cdot 20)$ & 0.02 \\
\hline WHO PS & $1.20(1.05-1.38)$ & 0.003 & & & & \\
\hline FLT3 & & & $1.44(1.19-1.73)$ & $<0.0001$ & $1 \cdot 36(1 \cdot 21-1 \cdot 53)$ & $<0.0001$ \\
\hline Biallelic CEBPA $^{\mathrm{MUT}}$ & & & $0.48(0.30-0.78)$ & 0.01 & $0.52(0.32-0.85)$ & 0.01 \\
\hline DNMT3AMUT & & & $1.26(1.04-1.53)$ & 0.02 & & \\
\hline NPM1MUT & $0.6(0.38-0.94)$ & 0.04 & $0.78(0.65-0.95)$ & 0.04 & $0.75(0.62-0.91)$ & 0.001 \\
\hline
\end{tabular}

Abbreviations: CR, complete remission; CR1, first remission; HR, hazard ratio; MUT, mutant; PS, performance status; WBC, white blood cell count

Table 2. Risk factors predicting for overall survival in multivariate analysis 


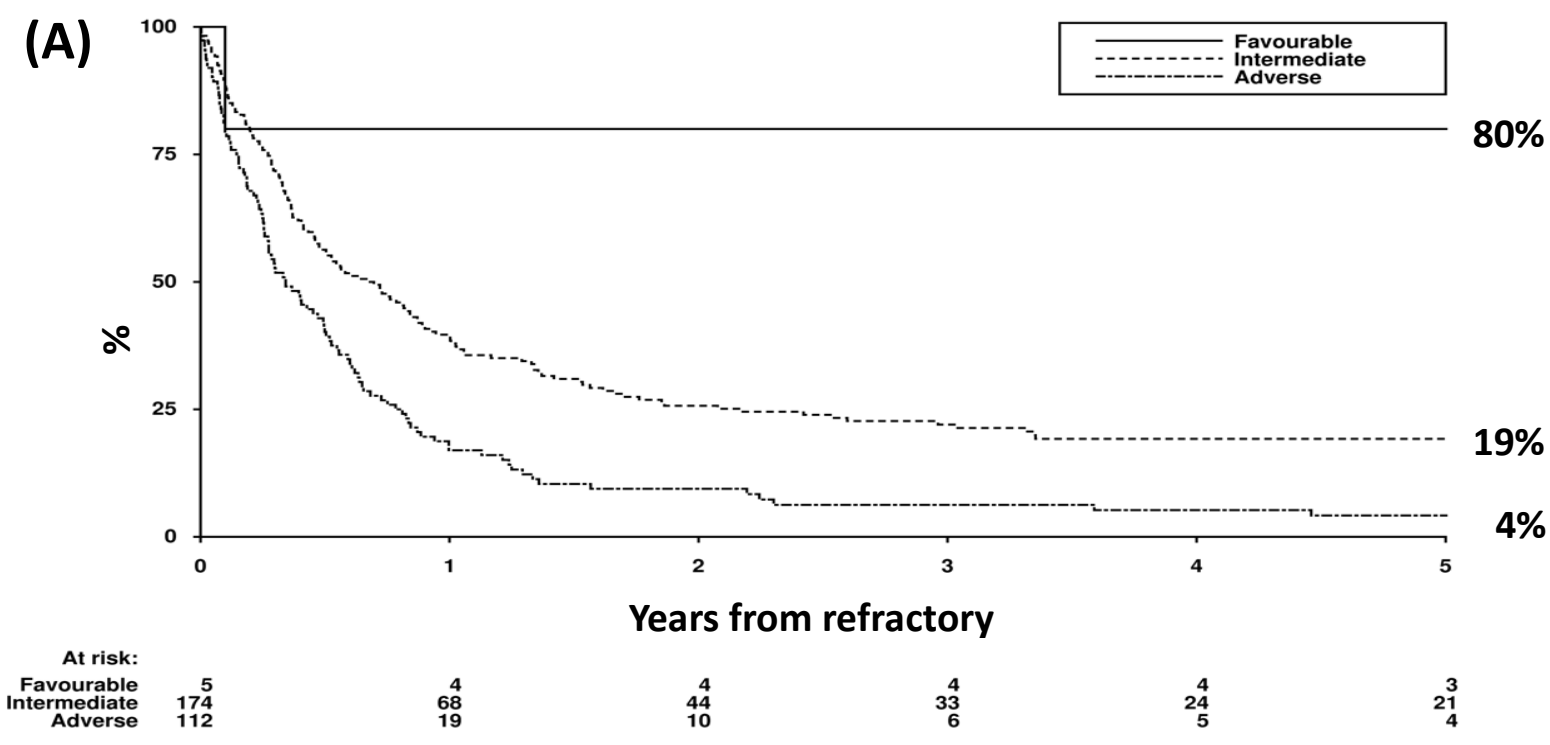

(B)

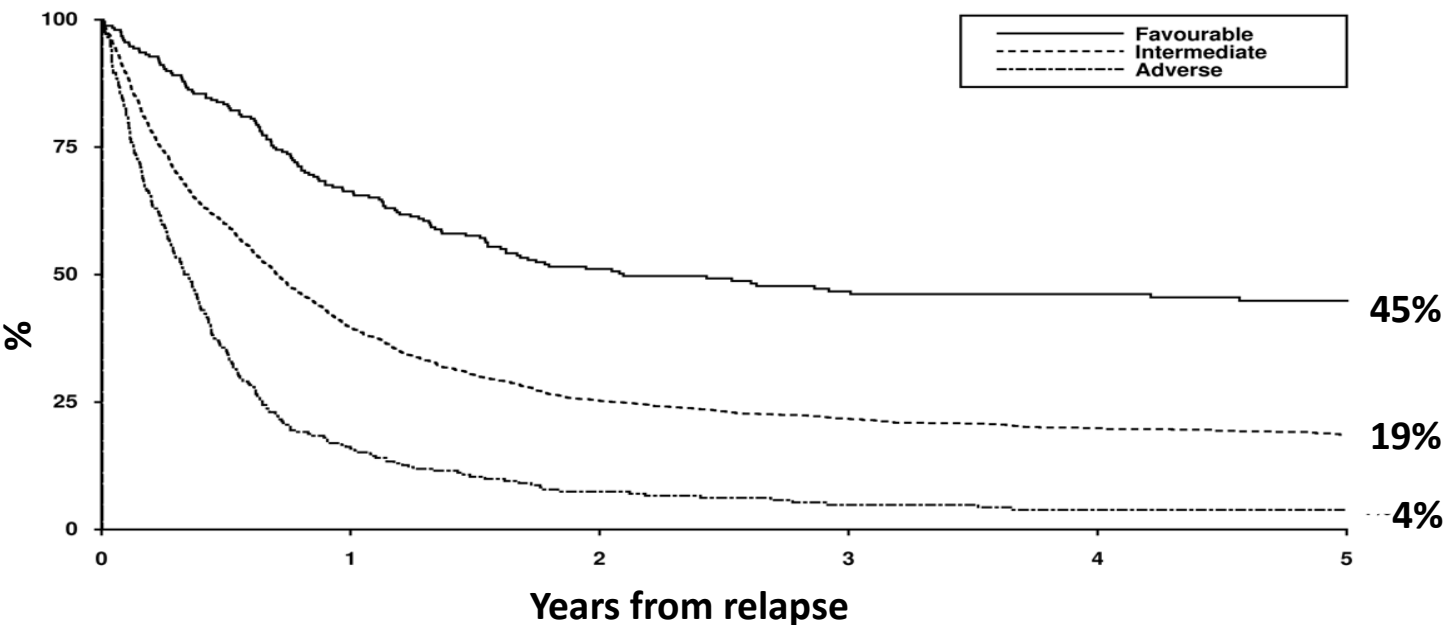

Years from relapse

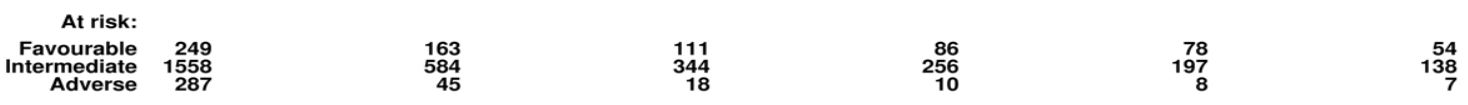

Fig. 1. Kaplan-Meier curves showing the impact of cytogenetic risk group on overall survival in patients with $(A)$ resistant disease, $(B)$ relapsed disease.

\subsubsection{Relapsed disease}

In patients with relapsed disease, many risk factors for the attainment of CR and OS were identified in both univariate and multivariate analysis including, as expected, cytogenetics, age, presenting WBC and duration of remission (Tables 1, 2). In patients with favourable-risk cytogenetics, $84 \%$ achieved CR2 and the survival at 1 and 5 years was $66 \%$ and $45 \%$ respectively. In patients with intermediate-risk cytogenetics, the CR2 rate was $50 \%$, OS at 1 year $39 \%$ and at 5 years $19 \%$. In 
patients with adverse-risk disease, the CR rate was $21 \%$, OS at 1 year $15 \%$ and at 5 years only $4 \%$ (Fig. 1B). The duration of the remission was also highly important (HR per 6 months 0.89 [0.860.93]; $p<0.0001)$. Patients in whom the duration of $C R 1$ was $\geq 12$ months had a $C R$ rate of $64 \%$ compared to $41 \%$ in those in whom it was $<12$ months $(p<0.0001)$. The OS from the time of relapse was also better in those with a longer CR1 ( $30 \%$ vs $13 \%$ at 5 years, $p<0.0001)$. In those who received a CR1 allograft, the CR2 rate was 32\% and survival following relapse was $26 \%$ at 1 year and $11 \%$ at 5 years, whereas for those patients who had not received a CR1 allograft the CR2 rate was 52\% and OS at 1 and 5 years 41\% and 21\% respectively (HR 1.35 [1.09-1.66]; $p<0.002$ ) (Fig. 2).

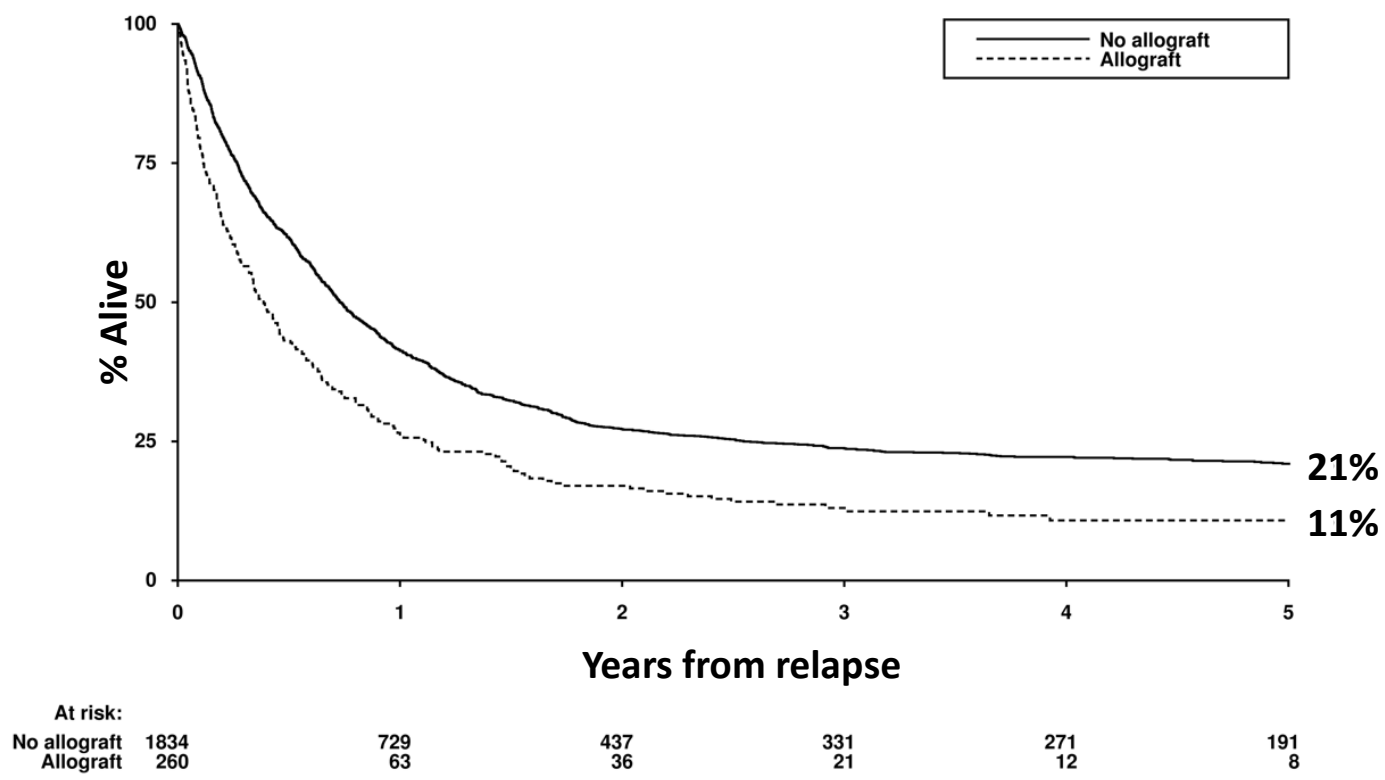

Fig. 2. Kaplan-Meier curve showing overall survival post-relapse in patients who received or did not receive an allogeneic transplant in first remission.

In view of this large difference in outcome between those who had and had not received an allograft in CR1, and the fact that treatment options are more limited in those who have already received an allograft, MVA of the prognostic factors was carried out just in those relapsed patients who had not received a CR1 allograft, but no major differences from the group of relapsed disease patients as a whole were identified (Table 2). 


\subsection{Prognostic significance of mutational genotype}

\subsubsection{Resistant disease}

The presence of an NPM1 mutation was a significant favourable factor for attainment of a later CR and for OS in patients with resistant disease ( $p=0.01$ and 0.03 respectively in univariate analysis). In NPM1 $1^{\mathrm{MUT}}$ patients, the ultimate CR rate was $48 \%$ and OS at 1 and 5 years was $36 \%$ and $31 \%$ respectively compared to a CR rate of $29 \%$ and OS at 1 and 5 years of $29 \%$ and $11 \%$ respectively in those with NPM1 wild-type (NPM1 ${ }^{\mathrm{WT}}$ ) disease (Fig. 3A). When NPM1 genotype was entered into the multivariate model, NPM1 ${ }^{\mathrm{MUT}}$ remained a significant independent factor for OS (HR 0.60 [0.380.94]; $p=0.04)$.

The presence of a FLT3 ${ }^{\text {ITD }}$ expressed in binary terms was associated with a lower subsequent CR rate $\left(26 \%\right.$ vs $32 \%$ in those without a $\left.F L T 3^{\mid T D}\right)$, but this difference was not significant $(p=0.3)$. OS at 1 year was also less in those with a $F L T 3^{\text {ITD }}(28 \%$ vs $43 \%)$, as it was at 5 years ( $11 \%$ vs $\left.14 \%\right)$, but this difference in survival was again not significant $(p=0.4)$. Of the $65 F L T 3^{1 T D}$-positive patients, the $F L T 3^{\mid T D}$ VAF was quantified in 42 . The CR rate was unrelated to the $F L T 3^{\text {ITD }}$ VAF $(p=0.7)$ but OS decreased as the mutant allele burden increased (Table 3), with those with a FLT3 ${ }^{\text {TD }}$ VAF $\geq 50 \%$ having a significantly worse $O S(p=0.01)$. Considering the combination of the NPM1 and FLT3 ${ }^{1 T D}$ mutational status, it is apparent that the improved outcome in NPM1 ${ }^{\mathrm{MUT}}$ patients is present in both those with and without a FLT3 ${ }^{1 T D}$ (Fig. 3B). The mutational status of the CEBPA, DNMT3A, IDH1 and IDH2 genes was also determined in a variable number of these patients (Table 1). None of the 138 patients genotyped for CEBPA had biallelic mutations, in accord with the fact that this is a good prognostic group with a very low rate of resistant disease [7]. Of those 131 patients genotyped for DNMT3A, there was a significantly better CR rate in those 29 (22\%) with a DNMT3A mutation $(p=0.003)$, and also a trend towards improved survival ( $21 \%$ vs $9 \%$ at 5 years, $p=0.06)$. This apparent paradox for a usually poor prognostic bio-marker is explained by the close concordance of DNMT3A and NPM1 mutations, with the latter associated with a good prognosis [11], and if the impact of $D N M T 3 A^{\mathrm{MUT}}$ was restricted to the NPM1 ${ }^{\mathrm{MUT}}$ patients, then the co-existence of a DNMT3A mutation was no longer a good prognostic feature $(p=0.4)$. Neither the presence of an IDH1 mutation (present in 13 of 168, 7.7\%) nor an IDH2 mutation (present in 23 of 213, 10.8\%) was associated with outcome in this cohort of patients in univariate analysis (for IDH1: HR of OS 1.17 [0.66-2.07], p=0.6; for IDH2: HR 1.22 [0.79-1.87], $\mathrm{p}=0.4)$. 
(A)

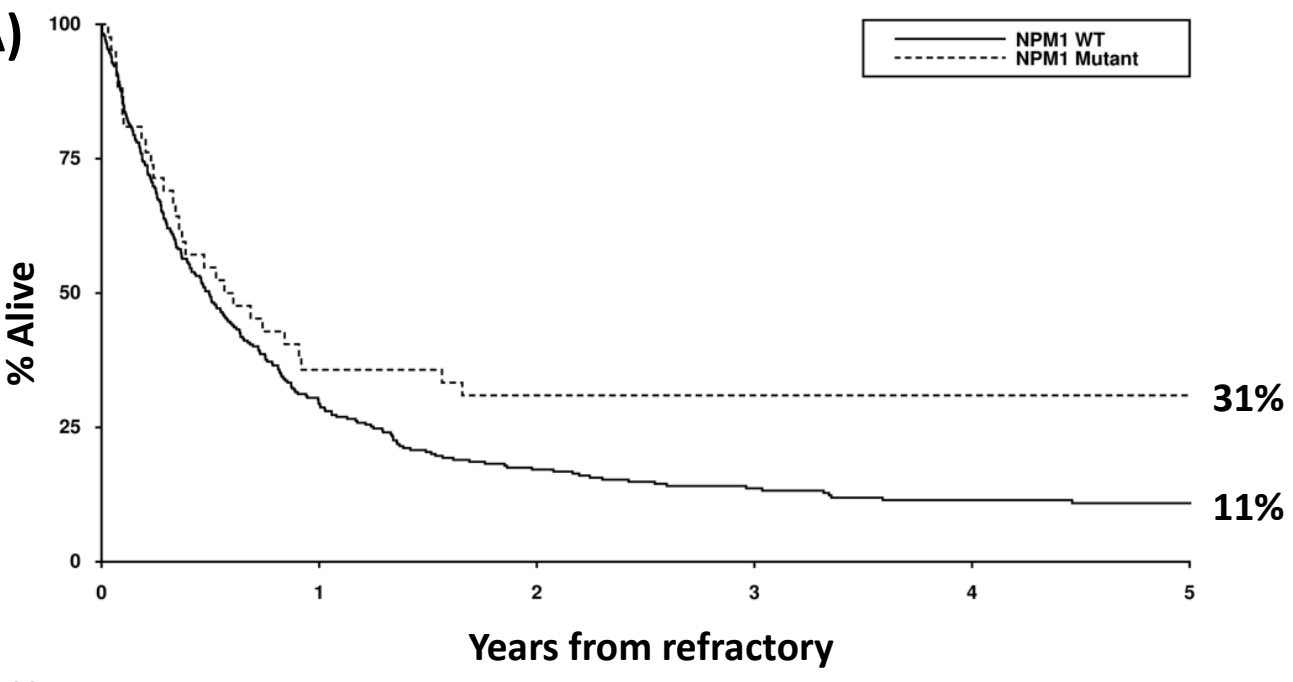

At risk:

NPM1 WT
NPM1 Mutant

83
15

${ }_{13}^{47}$

${ }_{13}^{32}$

23
12

$i^{2}$

(B)

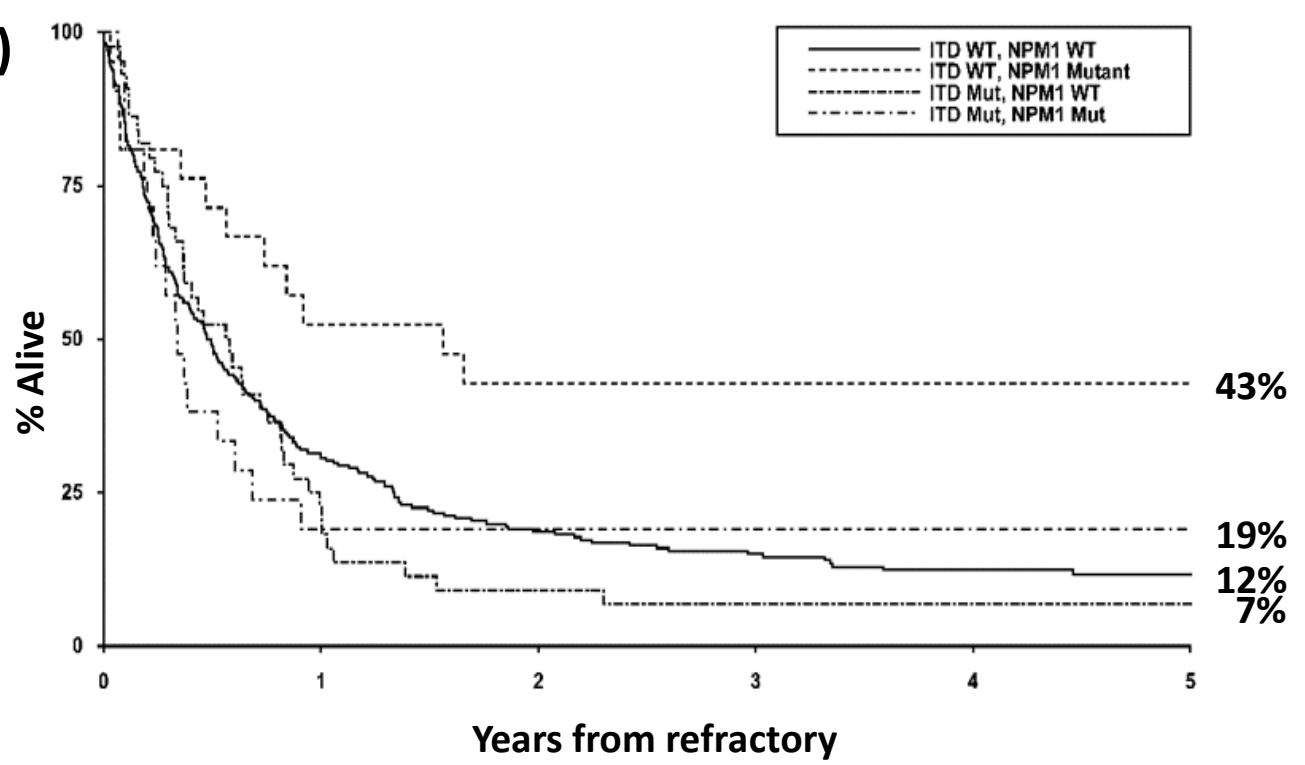

At risk:

ITD WT, NPM1 WT

D WT, NPM1 Mutant

ITD Mut, NPM1 WT
ITD Mut, NPM1 Mut

238
21
44
21

$\begin{array}{rr}73 & 43 \\ 11 & 9 \\ 10 & 4 \\ 4 & 4\end{array}$

30
9
2
4

$\begin{array}{rr}21 & 15 \\ 8 & 8 \\ 2 & 2 \\ 4 & 4\end{array}$

Fig. 3. Kaplan-Meier curves showing the impact of genotype on overall survival in patients with resistant disease. Patients were stratified according to $(A)$ the presence or absence of an NPM1 mutation, (B) the presence or absence of both an NPM1 mutation and a FLT3 ${ }^{\text {ITD }}$. 


\begin{tabular}{|l|c|c|c|c|c|c|c|c|}
\hline & \multicolumn{4}{|c|}{ Resistant disease } & \multicolumn{4}{c|}{ Relapsed disease } \\
\hline FLT3ITD VAF & $\mathrm{n}$ & CR rate & OS@1 year & OS@5 years & $\mathrm{n}$ & CR rate & OS@1 year & OS@5 years \\
\hline WT & 259 & $32 \%$ & $32 \%$ & $14 \%$ & 1739 & $54 \%$ & $44 \%$ & $21 \%$ \\
\hline$<25 \%$ & 12 & $42 \%$ & $42 \%$ & $17 \%$ & 79 & $37 \%$ & $27 \%$ & $14 \%$ \\
\hline $25-49 \%$ & 19 & $26 \%$ & $16 \%$ & $11 \%$ & 168 & $36 \%$ & $25 \%$ & $11 \%$ \\
\hline$\geq 50 \%$ & 11 & $27 \%$ & $0 \%$ & $0 \%$ & 47 & $21 \%$ & $6 \%$ & $2 \%$ \\
\hline
\end{tabular}

Abbreviations: CR, complete remission; OS, overall survival; VAF, variant allele frequency; $W T$, wild-type

\section{Table 3. Outcome according to $F L T 3^{1 \mathrm{TD}}$ variant allele frequency at presentation}

\subsubsection{Relapsed disease}

In relapsed disease, NPM1 genotype had no significant impact on survival when the whole group of relapsed disease patients were analysed in univariate analysis $(p=0.5)$, nor when the analysis was restricted to those who had not received a CR1 allograft $(p=0.3)$. However, the group of NPM1 $1^{\text {MUT }}$ patients is largely exclusive of those with favourable-risk cytogenetics, and in MVA NPM1 ${ }^{\mathrm{MUT}}$ did have a significantly beneficial impact on outcome (HR 0.78 [0.65-0.95]; $p=0.04$ ). This effect was slightly greater in those who had not had an allograft in CR1 (HR $0.75[0.6-0.91] ; p=0.01)$. In contrast to the situation in resistant disease patients, those patients that relapsed and had a FLT3 ${ }^{\text {ITD }}$ at diagnosis had a significantly worse survival (HR 1.44 [1.19-1.73]; $p<0.0001$ ), even when considered as a binary parameter. The FLT3 ${ }^{I T D}$ VAF was recorded in 294 of the patients, and this showed that even a low level VAF at diagnosis (<25\%) was associated with a reduced CR rate, although overall the impact of the $F L T 3^{1 T D}$ VAF on CR rate was not significant $(p=0.1)$ (Table 3). It was, however, associated with significantly reduced survival $(p=0.01)$. Patients with biallelic CEBPA mutations had a significantly improved survival from the time of relapse $(p=0.007)$. The presence of a DNMT3A mutation was also a significant adverse factor in MVA (Table 2).

With the addition of the mutational status to the standard risk factors in patients with relapsed disease, it was therefore possible to identify subgroups of patients with widely differing outcomes. Thus, in the 49 patients with a FLT3 ${ }^{I T D}$ VAF $\geq 50 \%$, the CR2 rate was only $21 \%$ and survival at 1 and 5 years $6 \%$ and $2 \%$ respectively. By contrast, in the 147 patients who had not had an allograft in CR1, had a CR lasting a year or more before relapse, and were FLT3 ${ }^{\mathrm{WT}}$ and $N P M 1^{\mathrm{MUT}}$ at presentation, the CR2 rate was $69 \%$ and survival at 1 and 5 years $64 \%$ and $36 \%$ respectively. 


\subsection{Impact of date of trial entry on prognostic factor analysis in both resistant and relapsed disease}

In resistant disease, there was no significant change in OS over the time course of the 4 trials $(p=0.5)$. In the cohort of relapsed patients, OS from the time of relapse did improve over the time period of analysis; compared to the most recent AML17 trial, the HR for the earlier trials was 1.28 (1.00-1.62) for AML15, 1.51 (1.26-1.82) for AML12 and 2.12 (1.68-2.68) for AML10 ( $p$ value for trend $<0.0001)$. In order to ascertain whether the value of the different prognostic factors identified changed over the time period of this study, prognostic factor risk scores were developed for both resistant and relapsed disease using the survival data shown in Table 2 and used to assess whether there was any interaction between the risk score and results from the last trial (AML17). No significant interaction was observed for patients with resistant disease $(p=0.2)$. Similarly, for relapsed disease, in spite of the improvement in OS with time, there was no evidence of significant interaction between prognostic factors over time $(p=0.1)$. These analyses suggest that there is little difference in the value of the prognostic factors identified between AML17 and earlier trials.

\section{Discussion}

The demographics of patients with resistant and relapsed disease are largely similar except that the proportion of patients with the different cytogenetic risk categories differs markedly. Patients with favourable-risk cytogenetics only rarely fail to achieve CR with 2 courses of induction therapy (2\% with resistant disease compared to $12 \%$ with relapsed disease, $p<0.0001$ ), whereas there is a considerably higher proportion of resistant disease patients with adverse-risk cytogenetics compared to those with relapsed disease ( $39 \%$ vs $14 \%, p=0.0004)$. Patients with resistant and relapsed disease also receive differing therapies, with relapsed disease patients having postinduction consolidation, in some cases including a CR1 allograft. It is commonly assumed that survival is similar in patients with either resistant or relapsed AML, as was the case in the GermanAustrian AML Study Group series $[17,24]$. In our series, however, the overall outcome of patients with resistant disease was worse than in those with relapsed disease, with CR rates after further therapy of $31 \%$ compared to $50 \%$ respectively $(p=0.0001)$ and 5 -year OS rates of $14 \%$ and $20 \%$ $(p=0.03)$. We would argue therefore, that these two disease categories should be analysed 
separately when considering prognostic factors or the results of new treatments in early phase trials.

In patients with resistant disease, the independent prognostic factors which predicted for OS, excluding mutational genotype, were the cytogenetic risk group, PS and presenting WBC, which is in accord with data from most previous series $[14,16,17]$. In our series, the percentage of blast cells at the time of the post-course $\# 2$ bone marrow had a major impact on outcome ( $p=0.0006$ in MVA), yet this parameter is rarely analysed; indeed, data was only available in $44 \%$ of our patients. It is perhaps not surprising that patients who nearly achieve a CR after two courses of induction therapy fare better than those who do not, and this should be taken into account in prognostication and decisions about further therapy. This finding inevitably raises the issue of the accuracy of morphological blast cell enumeration and, in view of its importance seen here, residual disease defined by morphological blast cell counts should be confirmed by flow cytometric or molecular means [25].

In patients with relapsed disease, the prognostic factors for survival included the cytogenetic risk group and WBC at presentation, as in resistant disease patients. Advanced age was also a poor prognostic factor. PS at presentation was not, however, a prognostic factor for survival, contrasting with the finding in resistant disease patients, presumably because PS at relapse bears only a limited relationship to the PS at presentation. A major determinant of outcome in relapsed disease patients was whether or not they had received a prior allograft, and separate consideration must be given to those who had or had not received an allograft consolidation of CR1. These findings are again broadly in accord with the previous literature $[12,14,16,24,26,27]$.

Molecular genotype in our large series clearly added further independent prognostic information in those with both resistant and relapsed disease. In patients with resistant disease, NPM1 ${ }^{\mathrm{MUT}}$ was associated with a significantly better attainment of CR and improved OS, which is in contrast to the study of Wattad and colleagues [17]. The reason for this difference is not clear, although the latter study used a different definition of resistant disease (blast cell percentage $>25 \%$ after the first cycle of induction therapy or less than a $50 \%$ reduction if the blast cell percentage at diagnosis was $<50 \%)$ and included older patients. In our relapsed disease patients, NPM1 ${ }^{\mathrm{MUT}}$ was also a significant good prognostic marker but this was only apparent in MVA and was more marked in those patients 
who had not received a CR1 allograft. It appears that the very poor prognosis associated with relapse after an allograft tends to negate any beneficial effects associated with an NPM1 mutation. In a previous report from Chevallier and colleagues [16], NPM1 ${ }^{\mathrm{MUT}}$ at diagnosis was only associated with a trend towards higher OS, and in a similarly combined Spanish series of both resistant and relapsed $A M L$ the NPM1 genotype bore no significant relationship to outcome [14]. It is not clear in those two series to what extent the different findings from ours with regard to NPM1 genotype relate to the cohorts combining patients with resistant and relapsed disease or to the inclusion of relapsed disease patients who had previously received an allograft. Schlenk and colleagues analysed relapsed disease patients alone and also found no impact of the NPM1 genotype [15], but the previous history of a consolidation allograft was not considered.

In patients with resistant disease, $F L T 3^{I T D}$ as a binary parameter (present/absent) was not significantly associated with outcome in MVA, but OS at 5 years was significantly worse in those with a $F L T 3^{\text {ITD }} V A F \geq 50 \%(p=0.007)$. In relapsed disease patients, FLT3 ${ }^{\text {ITD }}$ was strongly associated with a worse survival ( $p<0.0001$ in MVA), in accord with previous reports $[14,16,24,26,28]$, and our data further shows that the prognosis is particularly bad in those with a FLT3 ${ }^{I T D}$ VAF $\geq 50 \%$. Of note, both loss and acquisition of a FLT3 ${ }^{\text {ITD }}$ have been described at the time of relapse, the latter being more frequent $[29,30]$. It is likely, therefore, that the FLT3 status at the time of relapse will have even greater prognostic significance than at presentation. Our cohort also shows that the presence of biallelic CEBPA ${ }^{\mathrm{MUT}}$ remains a good-risk feature in relapse, as previously reported $[7,24]$, and that $D N M T 3 A^{\mathrm{MUT}}$ is an independent poor prognostic factor. Of note, we did not find IDH1 ${ }^{\mathrm{MUT}}$ to be associated with a worse prognosis in resistant disease, contrasting with data from Wattad and colleagues [17], but the number of $I D H 1^{\mathrm{MUT}}$ cases in our series was small and the power of the analysis for this mutation was low.

This study emphasises that patients failing first-line therapy are a very heterogeneous group and that outcome is affected by multiple factors. These factors, including the genotype, differ between those with resistant and relapsed disease; consequently, these populations should be analysed separately. In both populations, groups of patients could be identified with a relatively good outcome with OS at 5 years in excess of $35 \%$ and, conversely, some with a very poor survival of $<5 \%$. The extent of this variability can make the interpretation of single-arm studies difficult, and adequately powered randomised trials in genetically defined subgroups of patients failing first-line 
therapy can be logistically very challenging. One approach is to carry out individual patient matching analyses using the most recent large databases with adequate follow-up, such as the AML17 database of 1107 patients, as contained within the current analysis. This matching should take into account, as far as is possible, all the independent prognostic factors identified here, including the NPM1, FLT3, CEBPA and DNMT3A genotype and the FLT3 ${ }^{\text {ITD }}$ VAF. Indeed, a 'matched threshold-crossing' approach is being used in Germany to determine whether to escalate from a small single-arm study into a randomised comparison in a trial evaluating the efficacy of bortezomid in relapsed and resistant AML [15]. Any matched pairs analysis, based on multiple parameters using historical controls, is not a replacement for randomised trials [31], but in situations where adequately powered randomised trials are not possible, it may in some instances prevent the over-interpretation of Phase II studies.

Appendix A. Supplementary Table A.1, Supplementary Table A.2

Contributors DCL designed the study; AG and REG provided genotyping data; $D C L, R E G$ and RKH analysed the data; AKB and NR were principal trial coordinators and provided data; DCL and REG wrote the manuscript; all authors reviewed the manuscript.

\section{Declaration of interests}

The authors have no competing interests to declare.

\section{Funding}

This work was supported by Blood Cancer UK, formerly Leukaemia \& Lymphoma Research (grants 11005 and 14001) and the UK Medical Research Council. The work was undertaken at UCL Cancer Institute, which receives a proportion of funding from the Department of Health's National Institute for Health Research Biomedical Research Centres funding scheme. The funders and study sponsors had no role in study design, data collection, analysis, interpretation, writing of the report, or the decision to submit the paper for publication.

\section{Acknowledgments}

We thank the clinical investigators who entered and managed patients in these trials. 


\section{References}

1. Khwaja A, Bjorkholm M, Gale RE, et al. Acute Myeloid Leukaemia. Nature Reviews Disease Primers 2016; 2: 16011.

2. Dohner H, Estey E, Grimwade D, et al. Diagnosis and management of AML in adults: 2017 ELN recommendations from an international expert panel. Blood 2017; 129: 424-27.

3. Tallman MS, Wang ES, Altman JK, et al. Acute Myeloid Leukemia, Version 3.2019, NCCN Clinical Practice guidelines in Oncology. J Natl Compr Canc Netw. 2019, 17: 721-49.

4. Gale RE, Green C, Allen C, et al. The impact of FLT3 internal tandem duplication mutant level, number, size and interaction with NPM1 mutations in a large cohort of younger adult patients with acute myeloid leukemia. Blood 2008: 111: 2776-84.

5. Papaemmanuil E, Gerstung M, Bullinger L, et al. Genomic classification and prognosis in acute myeloid leukemia. N Engl J Med 2016; 374: 2209-21.

6. Wouters BJ, Löwenberg B, Erpelinck-Verschueren CA, et al. Double CEBPA mutations, but not single CEBPA mutations, define a subgroup of acute myeloid leukemia with a distinctive gene expression profile that is uniquely associated with a favorable outcome. Blood 2009;113: 3088-91.

7. Green CL, Koo KL, Hills RK, et al. Prognostic significance of CEBPA mutations in a large cohort of younger adult patients with acute myeloid leukemia: impact of double CEBPA mutations and the interaction with FLT3 and NPM1 mutations. J Clin Oncol 2010; 28: 2739-47.

8. Thiede C, Steudel C, Mohr B, et al. Analysis of of FLT3-activating mutations in 979 patients with acute myelogenous leukemia: association with FAB subtypes and identification of subgroups with poor prognosis. Blood 2002; 99: 4326-35.

9. Shivarov V, Gueorguieva R, Stoimenov A, et al. DNMT3A mutation is a poor prognosis biomarker in AML: Results of a meta-analysis of 4500 AML patients. Leuk Res 2013; 37: 1445-50.

10. Tie $\mathrm{R}$, Zhang $\mathrm{T}$, Fu H, et al. Association between DNMT3A mutations and prognosis of adults with de novo acute myeloid leukemia: A systematic review and a meta-analysis. PLoS One 2014; 9: e93353.

11. Gale RE, Lamb K, Allen C, et al. Simpson's paradox and the impact of different DNMT3A mutations on outcome in younger adults with acute myeloid leukemia. J Clin Oncol 2015; 33: 2072-83.

12. Breems DA, Van Putten WL, Huijgens PD, et al. Prognostic Index for adult patients with acute myeloid leukemia in first relapse. J Clin Oncol 2005; 23: 1969-85.

13. Kurosawa S, Yamaguchi T, Miyawaki S, et al. Prognostic factors and outcomes of adult patients with acute myeloid leukemia after first relapse. Haematologica 2010; 95: 1857-64.

14. Bergua JM, Montesinos $P$, Martinez-Cuadron D, et al. A prognostic model for survival after salvage treatment with FLAG-Ida +/- gemtuzumab ozogamicine in adult patients with refractory/relapsed acute myeloid leukaemia. Brit J Haematol 2016; 174: 700-10. 
15. Schlenk RF, Muller-Tidow C, Benner A, Kieser M. Relapsed/refractory acute myeloid leukemia: any progress? Curr Opin Oncol 2017; 29: 467-73.

16. Chevallier $P$, Labopin $M$, Turlure $P$, et al. A new leukemia prognostic scoring system for refractory/relapsed adult acute myelogenous leukaemia patients: a GOELEMS study. Leukemia 2011; 25: 939-44.

17. Wattad $M$, Weber $D$, Dohner $K$, et al. Impact of salvage regimens on response and overall survival in acute myeloid leukemia with induction failure. Leukemia 2017; 31: 1306-13.

18. Hann IM, Stevens RF, Goldstone AH, et al. Randomized comparison of DAT versus ADE as induction chemotherapy in children and younger adults with acute myeloid leukemia: Results of the Medical Research Council's 10th AML trial (MRC AML10). Blood 1997; 89: 2311-18.

19. Burnett AK, Hills RK, Milligan DW, et al. Attempts to optimize induction and consolidation treatment in acute myeloid leukemia: Results of the MRC AML12 trial. J Clin Oncol 2010; 28: 586-95.

20. Burnett AK, Russell NH, Hills RK, et al. Optimization of chemotherapy for younger patients with acute myeloid leukemia: results of the Medical Research Council AML15 trial. J Clin Oncol 2013; 31: 3360-68.

21. Burnett AK, Russell NH, Hills RK, et al. A randomized comparison of daunorubicin $90 \mathrm{mg} / \mathrm{m}^{2} \mathrm{vs} 60 \mathrm{mg} / \mathrm{m}^{2}$ in AML induction: results from the UK NCRI AML17 trial in 1206 patients. Blood 2015; 125: 3878-85.

22. Green $\mathrm{CL}$, Evans $\mathrm{CM}$, Zhao $\mathrm{L}$, et al. The prognostic significance of $I D H 2$ mutations in $\mathrm{AML}$ depends on the location of the mutation. Blood 2011; 118: 409-12.

23. Grimwade D, Hills RK, Moorman AV, et al. Refinement of cytogenetic classification in acute myeloid leukemia: determination of prognostic significance of rare recurring chromosomal abnormalities among 5876 younger adult patients treated in the United Kingdom Medical Research Council trials. Blood 2010; 116: $354-65$.

24. Schlenk RF, Frech $P$, Weber $D$, et al. Impact of pretreatment characteristics and salvage strategy on outcome in patients with relapsed acute myeloid leukemia. Leukemia 2017; 31: 1217-20.

25. Freeman SD, Hills RK, Russell NH, et al. Induction response criteria in acute myeloid leukaemia: implications of a flow cytometric measurable residual disease negative test in refractory adults. Brit J Haematol 2019; 186: 130-133.

26. Wagner K, Damm F, Thol F, et al. FLT3-internal tandem duplication and age are major prognostic factors in patients with relapsed acute myeloid leukemia with normal karyotype. Haematologica 2011; 96: 68186.

27. Rashidi A, Weisdorf DJ, Bejanyan N. Treatment of relapsed/refractory acute myeloid leukaemia in adults. Brit J Haematol 2018; 181: 27-37.

28. Ganzel C, Sun Z, Cripe LD, et al. Very poor long-term survival in past and more recent studies for relapsed AML patients: the ECOG-ARIN experience. Am J Haematol 2018; 93: 1074-81. 
29. Kottaridis PD, Gale RE, Langabeer S, et al. Studies of FLT3 mutations in paired presentation and relapse samples from patients with acute myeloid leukemia; implications for the role of FLT3 mutations in leukemogenesis, minimal residual disease detection, and possible therapy with FLT3 inhibitors. Blood 2002; 100: 2393-2398.

30. Warren M, Luthra R, Yin CC, et al. Clinical impact of change of FLT3 mutation status in acute myeloid leukemia patients. Mod Pathol 2012; 25: 1405-12.

31. Hills RK. Evaluating sixty years of UK trials research in acute myeloid leukaemia: lessons for trial design, past, present and future. Br J Haematol 2020; 188: 29-35. 